for policy and management both nationally and in transboundary regions, and improved national and international scientific collaboration.

The findings of the stakeholder surveys will feed directly into the development of a portfolio of competences and learning outcomes for the MSc programmes in a region that depends heavily on the sustainable management of abundant yet declining natural resources, often shared between neighbouring countries. The focus of CORRIENTE XXI on sustainable development skills, on graduate employability and on research-based higher education is in line with the objectives of the upcoming United Nations Decade of Ocean Science for Sustainable Development. For more information about the project, please contact Jean Hugé.

Diana Di NitTo and Nico Koedam Vrije Universiteit Brussel, Brussels, Belgium

JEAN HUGÉ (๑ orcid.org/0000-0002-3695-547X) Vrije Universiteit Brussel, Brussels, Belgium, and Open University of the Netherlands, Heerlen, The Netherlands

E-mail jean.huge@ulb.ac.be

Francisco Benitez-Capistros, LuCy BaLdeon Rojas, XaVIer BoliVAR LASTRA BRAVO and Dario AleXander CePEDA-BAstidas Universidad Central del Ecuador, Quito, Ecuador

Isabel Timpe-Vera, GLadys Rincon-Polo, Jonathan Cedeno and RAFAel BERMUDEz Escuela Superior Politecnica del Litoral, Guayaquil, Ecuador

Ana Asuncion Huamantinco Araujo Universidad Nacional Mayor de San Marcos, Lima, Peru

\section{1st Sharjah International Conservation Forum for Arabia's Biodiversity}

The 21st Annual Sharjah International Conservation Forum for Arabia's Biodiversity was held at the Breeding Centre for Endangered Arabian Wildlife in Sharjah, United Arab Emirates, during 3-6 February 2020. This Forum brought together over 180 participants from Jordan, Kuwait, Yemen, Bahrain, UAE, Saudi Arabia and Oman, and also from the UK, Germany, Canada, Denmark, South Africa, Australia and New Zealand. The Sharjah workshops are hosted by the Environment and Protected Areas Authority of the Government of Sharjah, under the patronage of H.H. Sheikh Dr Sultan bin Mohammed al Qasimi, Member of the Supreme Council and Ruler of Sharjah.

This was the first time the Forum has had a specific marine focus, chosen for 2020 to acknowledge the diversity and importance of the region's seas and oceans for biodiversity, and to broaden the reach of the Forum's primary objective, which is to promote conservation of the region's diverse and unique biota. The inclusion of the marine theme was particularly important this year as it provided an opportunity for regional marine scientists to begin preparations for the United Nations Decade of Ocean Science for Sustainable Development (2021-2030). This UN Decade was proclaimed to support efforts to address declines in ocean health and to create a common framework to ensure science can assist in creating improved conditions for sustainable development of the Ocean (en.unesco.org/ocean-decade).

Keynote speakers covered a range of regional topics, including the current conservation challenges facing coastal and marine biodiversity, coral reef status and restoration, fish and fisheries, cetaceans and dugongs, seabirds, mangrove restoration, marine protected areas and the projected impacts of climate change. Taxon-focused working groups considered the threats to and the conservation management needs for coastal and marine plants, corals, fish, seabirds and marine mammals. Common threats identified by the working groups included coastal development, pollution (particularly oil and plastics), overfishing, bycatch and the impacts of destructive fishing gear, desalination and climate change. Parallel veterinary components considered the care and management of seabirds, marine mammals and turtles. The challenges identified for improvement of marine research and conservation included the needs for greater transboundary cooperation between range states, adequate legislation, enforcement of existing legislation and expansion of representative marine protected area networks.

Outputs from previous Forum meetings are available from sicfab.ae/publications.

PHILIP SEDDON (৫ orcid.org/0000-0001-9076-9566)

Department of Zoology, University of Otago, Dunedin, New Zealand.E-mail philip.seddon@otago.ac.nz

GERHARD STEENKAMP Department of Companion Animal Clinical Studies, Faculty of Veterinary Science, University of Pretoria, Onderstepoort, South Africa

DAVID MALLON Division of Biology and Conservation Ecology, Manchester Metropolitan University, Manchester, UK, and IUCN/Species Survival Commission

HELEN SENN Royal Zoological Society of Scotland, Edinburgh Zoo, Edinburgh, UK

SARAH MAY ACT Parks and Conservation, Canberra, Australia

KEVIN BUDD and JANE BUDD Environment \& Protected Areas Authority, Breeding Centre for Endangered Arabian Wildlife, Sharjah, United Arab Emirates 